\title{
Assertion, Knowledge and Rational Credibility: The Scoreboard
}

(Forthcoming in Epistemic Reasons, Epistemic Norms and Epistemic Goals, ed. M. Grajner and P. Schmechtig. DeGruyter Berlin/Boston)

\author{
Mona Simion $^{1}$
}

\begin{abstract}
Recent literature argues that knowledge is not necessary for epistemically proper assertion. The most prominent competing account on the market imposes a weaker, rational credibility norm on assertion (RCNA); it is argued that (1) theoretical considerations, such as a priori simplicity, speak in favour of RCNA, (2) the weaker norm scores equally well when it comes to accommodating linguistic data and (3) KNA, as opposed to RCNA, has a hard time explaining cases in which assertions on lesser epistemic standings do not render the speakers subject to criticism.

This paper tips the balance back in favour of the knowledge norm (KNA). I argue that: (1) the argument for the a priori simplicity of RCNA does not go through; (2) KNA scores better when it comes to accommodating linguistic data; (3) KNA and RCNA are shoulder to shoulder when it comes to explaining blamelessness of speakers in breach of the norm and (4) KNA fares better than RCNA in terms of a posteriori simplicity.
\end{abstract}

\section{Introduction}

One must: assert $\mathrm{p}$ only if one knows that $\mathrm{p}$. Or at least that is what a very popular view on the epistemic normativity of assertion states. This has become known in the literature as the Knowledge Norm of Assertion (KNA). ${ }^{2}$

The locus classicus for the defence of KNA is Williamson (2000). ${ }^{3}$ At a first glance, the view has quite a lot going for it; namely, linguistic data concerning the

\footnotetext{
${ }^{1}$ University of St Andrews and KU Leuven Epistemology Group, Andreas Vesaliusstraat 2, Leuven 3000, Belgium; mis2@st-andrews.ac.uk; mona.simion@hiw.kuleuven.be; www.mona-simion.com ${ }^{2}$ This paper is only concerned with the necessity claim involved in the knowledge account of assertion. For a defence of the sufficiency claim, see e.g. Simion (2015), DeRose (2002).
} 
paradoxical nature of assertions of the form ' $p$ but I don't know that $p$ ', the fact that assertions can be challenged by the question 'How do you know that p?', and the intuitive impropriety of asserting lottery propositions.

However, in recent literature, KNA is taken by many to be too strong of a requirement. The most prominent competing account on the market ${ }^{4}$ imposes a weaker norm on assertion, and has been most notably defended, among others, by Douven (2006) and Lackey (2008). Roughly, the thought is that one should only assert $\mathrm{p}$ if $\mathrm{p}$ is rationally credible to one (henceforth, RCNA), where the epistemic status at stake is taken to be equivalent to knowledge-level justification - that is, whatever turns un-gettiered true belief into knowledge.

Defenders of RCNA argue that (1) theoretical considerations, such as a priori simplicity, speak in favour of RCNA, (2) the weaker norm will do just as fine in accommodating the above linguistic data too, and (3) KNA, as opposed to RCNA, has a hard time explaining cases in which assertions on some lesser epistemic standings do not render the speakers subject to criticism. As such, it is argued, RCNA scores better overall.

In response to (3), defenders of KNA have largely employed one incarnation or another of what has become known as 'the excuse manoeuvre'. That is, they have maintained that the cases put forth by JNA defenders feature speakers who, although non-knowledgeable, and therefore performing an impermissible speech-act, have a good excuse for it. However, due to its lack of value-theoretic backing, this strategy has been charged with ad-hoc-ness by the main proponents of RCNA.

Thus, at the end of the day, it looks as if things are not looking very good for KNA anymore. What we are being offered by its contenders is a fairly attractive counter-candidate norm that 1) imposes less stringent epistemic constraints on the speaker and 2) offers an a priori simpler explanation of the empirical data.

This paper's main ambition is to tip the balance back in favour of KNA. To this effect, I will first argue that the argument for the a priori simplicity of RCNA does not go through (\$2). Furthermore, I will show that KNA scores better on the second

\footnotetext{
${ }^{3}$ Among its main defenders also figure Hawthorne (2004), Turri (2011). Williamson also holds that knowledge requires probability one on one's evidence and that knowledge is the single constitutive norm for assertion. This paper stays neutral on these matters.

To be clear, though: by not committing to the constitutivity claim I do not mean to suggest that there might be instances of assertion that are not governed by KNA. On the account defended in this paper, there are none. I take it, though, that the constitutivity claim is stronger than that. That is, it looks as if the following is true of constitutive norms: if activity $A$ is constituted by only a single constitutive norm, $n$, and if one violates $n$ with near maximal systematicity, then one does not count as engaging in $A$. Given, though, that it seems that one can lie - and thus beak KNA - with near maximal systematicity and still count as asserting, this paper does not commit to the constitutivity claim.

${ }^{4}$ The truth norm of assertion, according to which one's assertion is epistemically permissible only if true, is the other main competitor on the market. This paper does not engage with this account. See e.g. Williamson (2000) for some related worries, and Weiner (2005) for a rejoinder on behalf of the truth account.
} 
front - that is, accommodating linguistic data ( 33$)$. Secondly, I will provide a unitary defence of KNA on the third front, sourced in the normativity of action in general, so as to avoid charges with ad-hoc-ness (\$4). Finally, in the fifth section, I will provide more reasons to believe that knowledge is the norm of assertion, reasons pertaining to the epistemic function plausibly associated with this speech act. In the last section I will conclude.

\section{Assertion and the 'Zeroth Law of Rationality'}

Igor Douven first introduced the 'scoreboard approach' to the debate. In his 2006 paper, he goes through a series of data and argues that, on balance, RCNA scores better in accommodating them than KNA. According to Douven, while both KNA and RCNA do an equally good job in explaining the empirical data, RCNA is to be preferred due to considerations pertaining to a priori simplicity $(2006,451)$. That is, Douven argues, RCNA is but an extension of what he dubs 'the zeroth law of rationality':

LR: Only $\varphi$ if it is rational for you to $\varphi$.

From this, Douven derives the equivalent principle for assertion (henceforth LRA):

LRA: Only assert $\mathrm{p}$ if it is rational for you to assert $\mathrm{p}$.

Furthermore, Douven goes along with Jonathan Adler (2002) in supporting the belief-assertion parallel - that is, the claim that belief is nothing but assertion to oneself. In the light of this, and by the plausible assumption that if it is rational for one to assert that $\mathrm{p}$, then it is rational for one to assert $\mathrm{p}$ to oneself, he derives:

RCNA: Only assert $\mathrm{p}$ if it is rational for you to believe $\mathrm{p}$,

As such, Douven argues, we are faced with the following situation: RCNA seems to be a mere extension to a fundamental principle of rationality, to wit, LR - to which, he argues, we are committed anyway (2006: 456). Furthermore, the extension is obtained by an application of a principle that is equally endorsed by Williamson (2000) - that is, the belief-assertion parallel.

Now, say that it turns out that RCNA deals with the linguistic data as well as KNA does. If that is the case, in absence of similar support for KNA - that is, support coming from things that we endorse on independent grounds - RCNA will 
just provide an a priori simpler explanation of the data, and will thus turn out to be the preferable account.

Let us, though, take a closer look at Douven's LR. Recall that what we are interested in is the epistemic norm governing assertion. As such, Douven $(2012,293)$ points out that the rationality at stake is going to be epistemic rationality, concerned with the purpose of maximizing epistemic utility. As such, on a first approximation, we can restate the principle as follows:

LR*: You must (epistemically): $\varphi$ only if it is epistemically rational for you to $\varphi$.

Further on, for the particular case of assertion, we get:

LRA*: You must (epistemically): assert $\mathrm{p}$ only if it is epistemically rational for you to assert $\mathrm{p}$.

By the belief-assertion parallel, we get:

RCNA*: You must (epistemically): assert $\mathrm{p}$ only if it is epistemically rational for you to believe $\mathrm{p}$.

However, there are two major problems with this move. First, Kelp (2014) identifies cases in which it looks as if it is epistemically rational for me to assert $p$ in spite of the fact that I have no justification whatsoever to believe $\mathrm{p}$. If that is the case, there is reason to believe that either the epistemic status at stake in RCNA is not knowledge-level justification, or the belief-assertion parallel does not hold. Here is Kelp:

Consider a case in which I am offered a million true beliefs for asserting that two plus two equals five. Given, as Douven (2008) himself accepts, that attaining a large body of beliefs with a favourable truth to falsity ratio is our epistemic goal, it would seem highly epistemically rational for me to make this assertion. After all, I will make great progress towards attaining my epistemic goal. At the same time, [...] I do not have justification for believing what I assert (Kelp 2014, 12).

Furthermore, what I will argue next is that, even if we leave Kelp's worries aside, ${ }^{5}$ Douven's argument still fails to go through. That is, in what follows, I will

\footnotetext{
${ }^{5}$ Notice that, arguably, this argument, at least in its present form, only goes through on an act consequentialist value theoretic assumption. Notice, also, that this assumption would create a similar
} 
point towards a missing link in Douven's argument which renders it incapable to offer support to his favourite account of assertion.

Let us first grant Douven, for the sake of the argument, that his derivation of RCNA* is fine. Recall, however, that Douven also wants rational credibility to stand for knowledge-level justification. Therefore, the claim Douven is making is actually stronger than RCNA*:

RCNA**: You must (epistemically): assert $\mathrm{p}$ only if you have knowledge-level justification to believe $p$.

As such, the argument seems to go along the following lines:

(1) You must (epistemically): only $\varphi$ if it is epistemically rational for you to $\varphi$.

(2) You must (epistemically): assert p only if it is epistemically rational for you to assert $\mathrm{p}$ (from (1)).

(3) Belief is assertion to oneself.

(4) If it is epistemically rational for one to assert that $p$, then it is epistemically rational for one to assert $\mathrm{p}$ to oneself.

(5) You must (epistemically): assert p only if it is epistemically rational for you to believe $\mathrm{p}$ (from (2), (3) and (4)).

(6) You must (epistemically): assert p only if you have knowledge-level justification to believe p. (from (5))

It becomes clear then that Douven misses an argument from (5) to (6); that is, an argument to establish the equivalence between rational credibility and knowledgelevel justification.

Note, though, that when first presented, the argument was not supposed to establish more than (5). That is because Douven (2006) does not take much of a stance with regard to what the notion of rational credibility in RCNA is supposed to stand for. Douven $(2006,459)$ does, though, gesture in the direction of Keith Lehrer's (1990) coherentist theory of justification, and in later personal

problem for any norm of assertion, including KNA; after all, we can always bring cases in which on a particular occasion one gains more epistemically by breaking the norm. This problem parallels the classical 'scapegoat' objection to act utilitarianism in ethics.

That is not to say, however, that, as things stand, Kelp's argument does not go through. After all, Douven does commit himself to a combination of RCNA and epistemic act consequentialism in several places, so it looks as if it is on his shoulders to refine his view in order to escape these worries. One way for him to escape this issue is by going for a milder value theoretic schema, say, a rule consequentialist one. That is, by arguing that respecting RCNA brings more epistemic gain overall, even though it fails to do so on some particular occasions. Of course, though, this might also open a bunch of rejoinder options for Kelp. Thus, given the complexity of this discussion, this paper limits itself to mentioning Kelp's worries and then setting them aside. Nothing in what follows rests on this. 
communication with several authors he acknowledges that he has knowledge-level justification in mind (see e.g. Kelp (2014) for discussion). In contrast, Lackey (2008, 128) explicitly states that knowledge-level justification is the epistemic status at stake.

Notice, however, that, at the end of the day, this does not help Douven much. Here is why: even if Douven were to not stand behind any particular account of rational credibility, his argument would end up equally supporting whatever norm of assertion that also comes with a well-defended norm for rational belief, including KNA. Inasmuch as rational credibility is supposed to stand for knowledge-level justification, both the KNA and RCNA defender need a further argument for their preferred account of normativity of belief in order to get support from Douven's 'zeroth law of rationality'. If that is the case, as things stand, Douven's argument offers as much support to KNA as to RCNA. To see this, let us have a look at the epistemic extensions of Douven's LR for belief:

LRB*: You must (epistemically): believe p only if it is epistemically rational for you to believe $\mathrm{p}$.

Given that Douven wants rational credibility to stand for knowledge-level justification, we get:

LRB**: You must (epistemically): believe p only if you have knowledge-level justification for $\mathrm{p}$.

Both of these principles state epistemic norms for belief. However, only the first is a direct instance of $\mathrm{LR}^{*}$. The second presupposes that it is epistemically rational for you to believe $\mathrm{p}$ if and only if you have knowledge-level justification for $\mathrm{p}$.

However, why shall we buy without further argument that epistemically rational credibility is knowledge-level justification and not some other epistemic standard? Many people in the literature argue for different epistemic norms for belief: truth and knowledge are the most common counter-candidates. ${ }^{6}$ Williamson himself, for instance, takes it that the epistemic norm for belief is knowledge - that is, one should only believe $\mathrm{p}$ if one knows $\mathrm{p}$.

As such, for Williamson, it is only epistemically rational to believe $\mathrm{p}$ if one knows that . $^{7}$ Therefore, Williamson's position is perfectly compatible with RCNA*: one must, indeed, only assert $\mathrm{p}$ if $\mathrm{p}$ is rationally credible to one, where $\mathrm{p}$ is rationally

\footnotetext{
${ }^{6}$ See Gibbons (2013) for discussion.

${ }^{7}$ While Williamson (2000) is unclear on whether rational belief is governed by a knowledge norm, in more recent work he openly stands behind this claim (e.g. his 2013 exchange with Comesana and Cohen).
} 
credible to one only if one knows that $\mathrm{p}$. Therefore, one should only assert $\mathrm{p}$ if one knows p. Thus, insofar as we are missing an argument for a knowledge-level justification norm for epistemically rational belief, Douven's derivation fails to offer support for his preferred norm over KNA.

To sum up: we have seen that, against Douven, RCNA, at least in the shape envisaged by its main proponents, misses independent theoretical support over KNA. If that is the case, all we are left with for our scoreboard are empirical data. This still does not mean much for KNA, though; after all, if the RCNA supporters are right, and the two norms do deal equally well with these data, there is still an argument to be made that one should go for the weaker norm on grounds of user-friendliness.

Thus, let us have a look at how the two fare when it comes to a posteriori adequacy and simplicity.

\section{Linguistic Data}

I have mentioned that KNA is strongly supported by linguistic data concerning: 1) The intuitive impropriety of asserting 'My ticket lost' before knowing the results of the lottery draw; according to the vast majority of the literature, lottery propositions are not knowable and therefore, by KNA, unassertable. 2) The fact that assertions can be challenged by the question 'How do you know that p?'; if knowledge is the norm of assertion, it makes sense that the hearer expects the speaker to know what he asserted. 3) The paradoxical soundingness of Moorean statements of the form ' $p$ but I don't know that p' (see below).

Now, defenders of RCNA would have it that their favourite norm does not fall far behind in these respects. Douven $(2006,2009)$ argues that, in terms of empirical adequacy, RCNA does as good as KNA in explaining all of the above. Here is how: by Douven's lights, the intuitive unassertability of lottery propositions is triggered by the fact that not only are they not knowable, but, in accordance with the most recent solutions to the Lottery Paradox ${ }^{8}$, they are not even rationally credible to one. Therefore, they are also unassertable by $\operatorname{RCNA}(2006,459)$. When it comes to explaining the 'How do you know?' challenge, Douven argues that, even if KNA is false, due to the mostly friendly epistemic environment we inhabit, we typically know what we assert; as such, it makes sense that hearers would assume it to be the case $(2006,469){ }^{9}$

This paper will not take issue with Douven's case in either of these two respects; that is mostly because I agree with Douven on the former and I find the latter fairly

\footnotetext{
${ }^{8}$ See Douven (2006) section (2) for a brief overview.

${ }^{9}$ Douven does acknowledge that the RCNA explanation falls short of the simplicity of that of KNA here.
} 
plausible. What I will, though, discuss in more detail is the RCNA explanation of the paradoxical soundingness of Moorean statements. I will argue below that not only does RCNA not fare as well as KNA in this respect, but it does not even come close to giving a satisfactory account.

\subsection{Moorean Statements}

It is widely acknowledged that KNA offers a very straightforward explanation of why sentences such as 'It is Wednesday but I don't know that it is Wednesday' and 'It is Wednesday but I don't believe that it is Wednesday' sound paradoxical to us. If knowledge is the norm of assertion, on the plausible assumption that knowledge distributes across conjunctions, one is in a good enough epistemic position to assert 'p but I don't know that p' only if one knows both conjuncts. However, since knowledge is factive, one only knows the second conjunct if it is true that one does not know that $\mathrm{p}$. But that contradicts knowing the first conjunct. Thus, according to KNA, one cannot meet the conditions for making a proper assertion of the form ' $p$ but I don't know that p' (Williamson 2000, 253). Furthermore, if KNA is true, it is plausible that when the speaker asserts that $\mathrm{p}$, the hearer is led to believe that she knows that $\mathrm{p} ;{ }^{10}$ therefore, when one asserts the second conjunct of a Moorean statement, one denies what one has led one's hearer to believe by asserting the first conjunct (Moore 1962, 277). Thus, KNA explains why the conjunction 'p but I don't know that $\mathrm{p}^{\prime}$ is not only unassertable, but it also sounds paradoxical.

It is easy to see that, by similar reasoning, KNA scores equally well when it comes to Moorean statements with belief. If, by KNA, one is supposed to know both conjuncts of the Moorean statement, given that knowledge implies belief, it follows that one has to 1) believe that $\mathrm{p}$ and 2) know that one does not believe that $\mathrm{p}$. Given, again, factivity of knowledge, one needs to 1) believe that $\mathrm{p}$ and 2) not believe that $\mathrm{p}$. Thus, the conditions for proper assertability of Moorean propositions with belief cannot be met and, again, on similar grounds as above, it makes sense that such statements sound paradoxical to the hearer.

At a first glance, RCNA does not seem to be able to give as good an explanation of the phenomenon, given that rational credibility is not factive. In his 2006 paper,

\footnotetext{
${ }^{10}$ In what sense does asserting $\mathrm{p}$ lead the hearer to believe that the asserter knows $\mathrm{p}$ ? The received view is that it is a matter of 'presenting oneself' as knowing; however, people do not usually go to much into detail about this. One thing: if it is an implicature that is at stake here, it will probably not be a mere conversational implicature, since it is clearly not cancellable. Most likely, what we are dealing with is a conventional implicature (non-cancellable); for more on this distinction, see Grice (1989, 25-39).
} 
Douven himself acknowledges the superiority of KNA on this front; thus, he argues that, while RCNA can also make sense of why Moorean statements come with a paradoxical flavour, KNA scores better in terms of simplicity. Douven's early explanation goes, roughly, along the following lines: first of all, notice that the champion of RCNA need not hold that Moorean statements are not assertable. All she needs is a good explanation of the fact that they sound paradoxical. Now, it is a fact that we do not encounter Moorean statements every day. If that is the case, it also makes sense that they sound odd to us, due to lack of exposure. Why is it, though, that we do not hear Moorean statements every day? Well, according to Douven, although KNA is strictly speaking false, it is the case that we typically know what we assert. That is, in normal, friendly environmental conditions, if $p$ is rationally credible to me, I also know that $\mathrm{p}$. Given this, Moorean sentences are extremey rarely uttered, therefore extremely rarely heard, which explains their oddsoundingness. As such, according to Douven, although RCNA does not offer an equally straightforward explanation as KNA for the oddity of Moorean statements, it is able to accommodate the data in a perfectly plausible way $(2006,474)$.

In later work, though, Douven (2009) comes back to the issue and concedes that his early explanation of the odd-soundingness of Mooreean sentences is vulnerable to charges with lack of empirical adequacy; after all, many expressions we do not often encounter do not seem to share the odd-soundingness of Moorean statements. Consider, for instance, 'John seeks a unicorn'; surely we do not hear this every day. Still, it seems clear enough that whatever is happening when one hears a Moorean sentence pertains to a completely different category of oddness than that of other sentences to which we have little exposure $(2009,363)$.

However, Douven (2009) argues that, on the bright side, on more careful examination, RCNA is able to do as good a job as the knowledge norm in accommodating the odd-soundingness of Moorean statements. That is because, according to him, not only are the latter statements not knowable, but, on a Bayesian analysis, they are also not rationally credible, and, therefore, unassertable. Roughly, the argument goes as follows: first, Douven assumes that one plausible and fairly weak requirement on rational credibility is that a person believes p rationally only if it does not readily follow strictly on the basis of the assumption of her rationally believing $p$ plus some fairly uncontroversial doxastic principles ${ }^{11}$ that her degrees of belief are not probabilities. Second, Douven proves that, if one assumes, towards a reductio, that one rationally believes Moorean sentences, it does follow that one's degrees of belief are not probabilities. Thus, Douven argues, Moorean sentences are not rationally credible and therefore not assertable.

${ }^{11}$ (1) if you rationally believe $\mathrm{p}$ and $\mathrm{q}$ you also rationally believe $\mathrm{p}$; (2) rationally believing some $\mathrm{p}$ requires believing that $\mathrm{p}$ is more likely than not, and (3) if you rationally believe some $\mathrm{p}$, then your degree of belief that you believe $p$ is at least as great as your degree of belief that you don't believe $p$. 
Even if we accept Douven's unassertability diagnosis, though, there are still two major problems for his account. First, even if RCNA is the norm of assertion, it is not immediately clear that laymen would immediately 'feel' that Moorean statements are unassertable by RCNA. After all, by Douven's own lights, Moorean statements are, at first glance, rationally credible to one - Douven himself granted their assertability by RCNA in his 2006. Furthermore, proving that Moorean statements are not rationally credible, as we have seen, required quite some amount of work: "it is not immediately clear that it could never happen that, for some $\varphi, \varphi$ is rationally credible to a person and at the same time it is rationally credible to this person that she does not know $\varphi$ " $(2009,363)$. But if it is not immediately clear to philosophers that this is the case, how can it be that it is as clear to laymen as to trigger such feeling of paradox?

Second, crucially, even if we put this problem aside, mere unassertability will not suffice for doing the intended work here. Recall that the KNA explanation of the paradoxical soundingness of Moorean statements had two essential components: first, there was the unassertability; second, the heard contradiction triggered by it. Notice, also, that the former without the latter would do quite a poor job in what empirical adequacy is concerned. After all, there are many sentences for which one cannot ever meet the conditions for assertability imposed by KNA; take, for instance, necessary falsehoods. By KNA, and given factivity of knowledge, ' $2+2=5$ ' is unassertable, due to it being necessarily false and, therefore, unknowable. However, just like in the case of 'John seeks a unicorn', the oddity involved in hearing someone assert ' $2+2=5$ ', if any, is definitely of a completely different sort than the paradoxical soundingness of Moorean statements. As such, it looks as if what completes the work for empirical adequacy for KNA's explanation of the latter is the heard contradiction triggered by what the hearer is led to believe by the assertion of the first conjunct, together with the assertion of the second.

We have seen that, according to Douven, Moorean statements are not rationally credible to one, and, therefore, by RCNA, not assertable. Now, similarly to the case of KNA, this result, on its own, will not do the intended work in accounting for the paradoxical soundingness at stake. To see this, consider the case of lottery propositions; we have seen that according to Douven, they are not rationally credible, and therefore, by RCNA, not assertable. However, again, if I assert 'My ticket did not win' in absence of any inside information about the draw, although I am criticisable for making an improper assertion, there is not much feeling of oddity there to be experienced by the hearer. Again, while merely unassertable propositions do trigger a feeling of impropriety, this still does not come close to the paradoxical soundingness of Moorean statements. To see this, consider, in contrast: 'My ticket did not win but I don't believe my ticket did not win'. 
If that is the case, Douven needs more for his argument to work. What needs to be the case is not only that Moorean statements are unassertable by RCNA, but also that this triggers their paradoxical soundingness. Recall the KNA explanation of the latter: knowledge is the norm of assertion, therefore when one asserts that $p$ one leads one's hearer to believe that one knows that $p$, which is contradicted by the second conjunct; therefore, the heard contradiction. Let us try to construct an RCNA account along similar lines: when I assert that $\mathrm{p}$ I lead my hearer to believe that $\mathrm{p}$ is rationally credible to me. Notice, however, this does not contradict the second conjunct in any of the two Moorean schemas that we have been looking at. Take, for instance, the case of someone who is (irrationally) afraid of flying and consider his relationship to the proposition 'Flying is the least dangerous mode of transportation'. Even if the corresponding Moorean sentences are not rationally credible to her, it is certainly not contradictory for that person to say that $\mathrm{p}$ is rationally credible to her but she doesn't know or believe it. As such, it looks as if Douven is still missing an explanation of the paradoxical soundingness of Moorean sentences.

\section{The 'Blameless Asserter' Objection}

Recall that, according to its objectors, KNA-Nec has a hard time explaining cases of assertions on lesser epistemic standings which intuitively do not render the speaker subject to blame. Furthermore, according to the same objectors, the several lines of the defence employed by KNA champions suffer from some degree or another of ad hoc-ness. That is, the KNA-friendly responses available in the literature employ one variety or another of what has become known as 'the excuse manoeuvre'; roughly, the latter consists in arguing that, although in breach of the norm, the speakers in the problem cases have a good excuse for having broken it. ${ }^{12}$ Surprisingly enough, however, no general account of excusability is being offered; furthermore, in several cases, the claim seems to be tailor-made to fit the KNA defence against one charge or another, as the manoeuvre does not seem to work similarly well when it comes to the normativity of action in general. ${ }^{13}$ As such, the epistemological literature suffers greatly from the lack of a detailed account of blame attribution: ${ }^{14}$ many of the charges with ad hoc-ness brought by opponents of KNA are sourced in the fact that a clear and complete account of blame attribution is not being offered. What I will do

\footnotetext{
${ }^{12}$ For several incarnations of the excuse manoeuver, see, e.g., Williamson (2009), De Rose (2002) and Turri (2011). For charges with ad hoc-ness, see, e.g. Lackey (2007) and Douven (2006).

${ }^{13}$ See, e.g., De Rose's (2002) distinction between primary and secondary propriety, and Lackey's (2007) reply, dismissing the respective distinction on grounds of lack of fit with the normativity of action in general.

${ }^{14}$ Only very recently, people like Tim Williamson and Clayton Littlejohn have started taking steps in this direction (see their forthcoming papers on the issue).
} 
next is try to fill this gap. Assertion is a type of action; thus, in what follows, I will put forth a framework for the normativity of assertion in line with what I take to be a fairly uncontroversial framework for the normativity of action in general, so as to escape charges with ad-hoc-ness. Also, to the same purpose, I will put forth a fairly detailed and wide picture of blame attribution, although I will not need to appeal to it in its entirety for the purposes of this paper.

\subsection{Blame and Action}

Let us begin by making some necessary distinctions, in order to clear the normative air a bit. In the literature concerned with the relationship between an agent's blameworthiness and the impropriety of her action according to a particular norm governing its type - call it norm $\mathrm{X}$ - one can identify (at least) four fairly uncontroversial ways in which the two can come apart: ${ }^{15}$

Blame-Action1: An agent is blameless for performing a token act which is improper according to norm $\mathrm{X}$ if it is an all-things-considered proper act, unless she believes ${ }^{16}$ it to be all-things considered improper;

Blame-Action2: An agent is blameworthy for performing a token act which is proper according to norm $\mathrm{X}$, but is all-things-considered improper, with the following exceptions:

Blame-Action 2.1: An agent is blameless if she performs an all-things-considered improper act due to her performance not being under her control, provided that it is not the case that it should have been under her control.

Blame-Action 2.2: An agent is blameless for performing an all-things-considered improper act if she conformed to her epistemic duties and she had good reasons to believe she was respecting the norm.

To see how this goes, notice, first, that actions are governed by several norms in virtue of their being actions as such (prudential, moral etc.). But also, actions are subject to norms specific to the particular type they belong to: chess moves to rules

\footnotetext{
${ }^{15} \mathrm{I}$ am not aiming to offer an exhaustive account regarding blame attribution, but only to identify those instances which are fairly uncontroversial. For discussion, see e.g. Haji (1998), Zimmerman (1997).

${ }^{16}$ See footnote 19 .
} 
of chess, driving to traffic norms etc. As such, it might be that your act is proper $^{17}$ in one sense, but improper in another. Also, an act can be subject to an all-thingsconsidered evaluation. Requirements according to a particular norm are defeasible: they can be overridden by the requirements of other norms stepping in. For instance, promising your friend Ted that you are going to meet him for lunch and not showing up is improper according to the norms of social commitment, which essentially govern promise keeping. If you meet an injured stranger on the way to lunch, though, and you're the only one around to help him get to the hospital, then this further state of affairs overrides your prima facie obligation to meet Ted for lunch. Thus, blameworthiness will not necessarily be attached to acts which are improper according to a particular norm $\mathrm{X}$, as they might be all-things-considered proper. If you do decide to help the injured stranger instead of joining Ted for lunch, your breaking your promise remains improper according to the norms of social commitment; however, your act is, all-things-considered, perfectly fine, due to moral considerations stepping in. Also, you are not worthy of blame for performing it.

Secondly, it might be that your act is improper on all grounds, as there's no requirement keeping you from conforming to norm $\mathrm{X}$, but you are still blameless for breaking it. The classical case is one in which you violate the norm because ${ }^{18}$ your action is not under your control, say, because you have been brainwashed into performing it. Second, according to a fairly uncontroversial view in the literature ${ }^{19}$ that has been with us since Aristotle, one is an apt candidate for blame for violating a norm only if one is aware of what it is one is doing or bringing about (NE, 1110a1111b4). As such, one may reasonably do something impermissible because one reasonably but falsely believes it to be permissible. If you fail to keep your promise to Ted because your (otherwise highly reliable) secretary misinforms you about the time at which you're supposed to meet him, you're blameless for not showing up. However, breaking your promise remains an improper act according to the norms of social commitment.

With regard to this, some qualifications are needed. The literature (e.g Zimmerman (1997)) distinguishes between direct and indirect blameworthiness for performing an action. One is indirectly blameworthy for something $\mathrm{x}$, if and only if one is blameworthy for it by way of being blameworthy for something else, $y$, of which $\mathrm{x}$ is the consequence.

\footnotetext{
${ }^{17}$ I follow the literature on norms of assertion (e.g. DeRose 2002) in using propriety and permissibility interchangeably. Some philosophers would disagree with this, due to phenomena related to suberogation. However, nothing here hinges on this.

${ }^{18}$ The 'because' here is crucial to blamelessness. See Harry Frankfurt (1969).

${ }^{19}$ See e.g. Haji (1998), Zimmerman (1997). People working in this field disagree whether a belief or a knowledge condition is appropriate for blameworthiness. Although not much in this paper hinges on this, I here go with the stronger view - supporting the belief condition - in order to stay on the safe side by attributing blameworthiness more generously.
} 
One could be indirectly blameworthy for performing an action out of ignorance, by being directly blameworthy for being ignorant. ${ }^{20}$ Notice, though, that in the above case, although the agent ends up with a false belief that his action is in accordance with the relevant norms, this seems to happen through no fault of his own. That is, he seems to have conformed to his epistemic duties: asking your secretary about your schedule for the day is quite a reliable way to go about it. Surely, if our agent were to be late for lunch due to his trusting his three years old son's testimony about his schedule, we would tend to find him blameworthy for his breaking the norms of social commitment. ${ }^{21}$

\subsection{Bad Assertions, Good Asserters}

To sum up: assertion is a type of action. Given that we have identified at least four instances in which the propriety of the action and the blamelessness of the agent can come apart, it follows that we will not be able to trace whether a particular norm $\mathrm{X}$ governs assertion or not by merely identifying instances of blamelessness/blameworthiness of the speaker. However, most cases put forth by KNA objectors are not intended to do more than this in the first place. Lackey, for one, purports to "show that there are cases in which a speaker asserts that $p$ in the absence of knowing that $\mathrm{p}$ without being subject to criticism [...], thereby showing that knowledge cannot be what is required for proper assertion" $(2007,594)$. On a similar line, Douven argues that "if breaching a rule makes one blameworthy, which typically it does, then, [in these cases], on the knowledge account, the asserter comes out as being blameworthy, contrary to intuition" $(2006,477)$.

There are three types of cases put forth in the literature to this aim: assertion on (i) rational credibility in absence of belief, (ii) justified false belief, and (iii) justified true belief that falls short of knowledge.

(i) Assertion on rational credibility in absence of belief:

CREATIONIST TEACHER: Stella is a devoutly Christian fourth-grade teacher; as such, she strongly believes in the truth of creationism and, accordingly, in the falsity of evolutionary theory. Despite this, Stella fully recognizes that there is an

\footnotetext{
${ }^{20}$ Similarly, even if an action was not under your control, it might be that the action should have been under your control (e.g. you lack control of your driving for having been drinking before getting behind the wheel).

${ }^{21}$ It might also be that your belief is unjustified yet blameless-say because you have been brainwashed into believing your 3-year-old son on this. Notice that this case falls under the 'control' condition.
} 
overwhelming amount of scientific evidence against both of these beliefs. Stella regards her duty as a teacher to include presenting material that is best supported by the available evidence. As a result, while presenting her biology lesson today, Stella asserts to her students, "Modern day Homo sapiens evolved from Homo erectus," though she herself neither believes nor knows this proposition (adapted form Lackey $(2007,548))$.

Lackey argues that Stella "offers an assertion in the absence of knowledge and is not properly subject to criticism" (2007, 549).

I agree with Lackey that Stella is hardly blameworthy for her assertion. However, it looks as if the prudential constraint is the one dictating this intuition. To see this, consider: if I believe in witches, for instance, prudentially it would be best to not disclose that to my group of friends, as it might seriously affect my public image. Thus, when asked, I will go with the scientific view point and assert: 'Witches do not exist'. Surely, I can hardly be subject to blame for this. Recall, also, that in line with action in general (Blame-Action1), a speaker is not blameworthy for making an assertion which is improper according to norm $\mathrm{X}$ governing its type if it is all-thingsconsidered proper. Again, by Lackey's own lights, "Stella regards her duty as a teacher to include presenting material that is best supported by the available evidence" (my emphasis). Plausibly enough, given the usual norms governing the activity of teaching - that is, "presenting students with material that is best supported by the available evidence" - Stella is all-things-considered blameless, as more stringent requirements are overriding the epistemic norm governing her assertion. This, however, in no way implies that her assertion is proper according to the latter. To see this, imagine how Stella's KNA-proper assertion would have looked like:

CREATIONIST TEACHER - KNA: I don't know how our species came into being. Evolutionary theory says that Homo sapiens evolved from Homo erectus, but I don't believe that's true. I believe that men were created by God, but I have no scientific evidence that this is so.

Would we really want this to be what our children get from their biology course? Certainly not. Prudentially, Stella's assertion is surely impermissible. In fact, I trust that Stella would soon lose her job if she were to keep this kind of assertions coming. Which is nicely explained by Blame-Action2. To see this, let us change the structure of the audience: imagine that Stella would make the KNA-proper assertion in a conversation with her mother. Surely, we will no longer think she deserves criticism in this case.

(ii) Assertion on justified false belief: 
FAKE SNOW: [...] it is winter, and it looks exactly as it would if there were snow outside, but in fact that white stuff is not snow but foam put there by a film crew of whose existence I have no idea. I do not know that there is snow outside, because there is no snow outside, but it is quite reasonable for me to believe not just that there is snow outside but that I know that there is; for me, it is to all appearances a banal case of perceptual knowledge. Surely it is then reasonable for me to assert that there is snow outside (Williamson 2000, 257).

And

(iii) Assertion on justified true belief that falls short of knowledge:

FAKE BARNS: [...] suppose that Wendy correctly sees the only real barn that, unbeknownst to her, is completely surrounded by barn facades and asserts to me "There was a barn in the field we just passed" on this basis (Lackey 2007, 544).

In both the cases above, speakers assert from what they mistakenly take to be knowledge. And, intuitively, and according to RCNA champions, they can hardly be subject to blame. Also, notice that no further normative constraints seem to be active in these cases. As such, according to Douven, "someone who [...] on the basis of what seems to be excellent evidence, reports about the issue, [...] appears not to have done anything for which she would need an excuse - even if what, to the best of her knowledge, is true is in fact false" (2006: 480).

Notice, though, that even if Douven is right, the fact that the speaker is in no need of an excuse need not imply that her action was proper. The speaker in FAKE SNOW walks free (by Blame-Action2.2), for he has broken the relevant norm blamelessly; this does not mean, however, that this assertion must therefore be proper also. Similarly to your blamelessly breaking your promise to meet Ted for lunch due to being misinformed by your secretary, the speaker in FAKE SNOW blamelessly breaks KNA, since he had good reasons to believe he was respecting the norm. Perception is a pretty reliable way to come to believe it is snowing outside, just as testimony from a reliable secretary is a good source for beliefs regarding one's schedule.

To see that what we have here is a blameless speaker performing an improper speech act, think about what the attitude of the speaker should be towards her assertion after finding out that she was mistaken or gettiered: it looks as if one should take back the initial speech act and not stand by the commitments implied by it anymore. Thus, rather than presenting excuses as such, an appropriate reaction would go along the lines of "Oh, I take that back. I was not aware of there being a 
film crew producing fake snow outside", or "Oh, I take that back, I had no idea we were in Fake Barn County". This suggests that what we are dealing with is a speaker having blamelessly performed an improper speech act.

In reply to this line of defence, Jonathan Kvanvig (2009), however, argues that "in some cases of correction, we take back the content of our speech act, and in other cases we apologize for, and regret, the very act itself". ${ }^{22}$ For instance, if we assert $p$ and then are shown that $\mathrm{p}$ is false or that we have been gettiered, we take back the content of our speech act, but we needn't apologize for or regret the very act itself. In contrast, Kvanvig argues, when you don't have justification for what you say, apologizing and taking back the speech act itself is the right thing to do. Kvanvig argues that, given that norms of assertion are norms governing a certain type of human activity, they relate to the speech act itself, not to its content.

I have defended KNA against Kvanvig's 'two ways of taking back' argument in more detail in previous work (Simion 2014), thus I will only give a sketch of a reply here and, further on, attempt to accommodate some worries about it: speech act literature distinguishes between the content of a speech act and the illocutionary force by which the content is being put forward. One can perform various speech acts upon $p$ : one can ask whether $p$, promise that $p$, threaten that $p$ etc. In the case of assertion, by uttering $\mathrm{p}$ the speaker presents $\mathrm{p}$ as true. Given this, however, a proposition is itself communicatively inert; ${ }^{23}$ that is to say that to actually perform a speech act, one has to put forth a proposition with an illocutionary force, such as assertion, promise, command, etc.

But if the propositional content is inert in isolation, it is less clear how one can take it back in isolation. To see this, notice that assertion, as opposed to other types of actions - say, vacationing in Hawaii - can be 'taken back'. Not by changing the past, of course, but by no longer standing behind the commitments implied by asserting that $\mathrm{p}$. Now, $\mathrm{p}$ itself, in isolation, does not imply any commitments whatsoever. That is, depending on which illocutionary force we will act upon it with, different commitments will follow. If I promise that $p$, I commit myself to a future course of action; if I assert that $p$, I commit myself to it being the case that $p$.

But if that is the case, in order to take an assertion back, that is, to be released from the commitments implied by it, it has to be the case that I take back everything, force and content. I cannot only take back the content $p$, because $p$ in isolation does not commit me to anything, inasmuch as I do not present it as true, or command $\mathrm{p}$, or promise $\mathrm{p}$, etc. Also, on similar gorunds, I cannot only take the action back either.

Something is, indeed, different between the two cases presented by Kvanvig, though. By Blame-Action 2.2, the speakers in FAKE SNOW and FAKE BARNS,

\footnotetext{
${ }^{22}$ Kvanvig (2009) defends a Justified Belief Norm of Assertion.

${ }^{23}$ For more on this, see Green (2009).
} 
asserting on justified belief, are epistemically blameless. As opposed to that, asserters missing any justification whatsoever are indirectly blameworthy, as they failed to conform to their epistemic duties before proceeding.

To sum up: we have seen that Kvanvig's distinction did not manage to stand tall in the face of close speech-act-theoretic scrutiny. We have also seen that the normative framework put forth by this paper is perfectly able to accommodate the target phenomena in a KNA friendly way. However, the KNA objector might still maintain that that's not all there is to it; that is, that all this does not go all the way in showing that the phenomenon of taking back one's speech act when finding out one has been mistaken or gettiered supports KNA. The thought would go along the following lines: there seems to still be sense to the thought that some of the acts we take back were perfectly proper. Imagine I promise to come to your party. Plausibly enough, there's some norm of promising to the effect that you should only promise to do something you have good reason to think you will be able to do. Now say I can't come to your party, because of an entirely unforeseen event. It makes sense to say that, even though I ask to be released from the commitment to come, my original act of promising was perfectly proper. I need not apologise for having promised, or regret having promised. Why? Because I didn't do anything wrong. Why can't we say something parallel about assertion? When it turns out I was gettiered, I 'take back' my assertion (act and content), but I need not apologise for having asserted, or feel any regret. Why? Because I didn't do anything wrong. ${ }^{24}$

Notice, though, that the claim made by this paper is not a biconditional: all I claim is that taking back of speech acts is sufficient for asking to be released from the relevant commitments, not that it is necessary. That is, it is perfectly compatible with the claim made here that there will be instances of commitment release demand that do not amount to taking back the relevant speech act. What I will try to briefly argue next is that this is what is going on in the case above.

To see this, note there is a clear disanalogy between the party case and the gettiered assertion case. That is, by stipulation, in the party case my reason for promising to come, while still standing, gets overridden ${ }^{25}$ by unforeseen, more pressing considerations; in contrast, Wendy's reason to assert in the first place gets undercut by the information that she is in Fake Barn County.

To see how this makes a difference, consider another speech act, that of agreeing to marry someone. If I agree to marry you because I think you love me, and it turns out you don't, I will most likely take my speech act back and thereby ask to be

\footnotetext{
${ }^{24}$ Thanks to an anonymous referee for pressing me on this point.

${ }^{25}$ Again, I am not claiming that overriding is necessary for cases of commitment release demand without taking back the initial speech act; in general, it is beyond the ambition of this section to give a full account thereof. Rather, the thought is more to argue that KNA, through the normative picture put forth by this paper, can accommodate the target phenomena.
} 
released from my commitment. In contrast, if after twenty happy years of marriage we are not getting along very well anymore, and I ask for a divorce, I am asking to be released from my commitments without taking my initial speech act back; surely, if we had a perfectly fine marriage for twenty years, it is hardly appropriate or necessary for me to take back my having agreed to marry you to begin with, rather than merely ask to be released from my commitments now.

Returning to the assertion/party cases, say my reason to promise to come to the party was a known fact: I knew that my partner wanted to go. Say that later on, however, something unforeseen came up at my office, and it turns out I have to work late and finish a project that evening. As such, while my initial reason is still in good standing, it has just been overridden by more pressing considerations. It looks as if, in this case, there is no reason for me to take back my initial speech act, rather than merely demand to be released from the commitment implied by it. That is, it would sound inappropriate if I were to tell you something along the lines of 'I take it back, I should not have promised to come when I did'. Rather, merely letting you know that I will not be coming after all, due to unforeseen events, seems more suited to the situation.

In contrast, in the Gettier case, when I point out to Wendy that there is no way in which she can know that there is a barn over there, since we are in Fake Barn County, her initial reason to believe the asserted proposition gets undercut, which makes taking back the speech act the appropriate move. To see this, here is how an assertion case analogous to the party case would look like: I know there is an opening in my department, therefore I tell you: 'There is an opening in my department. I therefore commit myself to this being the case. Now say that the very next day the position gets filled. Plausibly enough, when I tell you that there is no opening in my department anymore, I am not taking my initial assertion back - there was nothing wrong with it - but rather I am merely releasing myself from the commitment to there being an opening in my department, since that is not the case anymore.

\section{The Scoreboard}

Let us take stock and revisit the scoreboard: we have seen that, against Douven, RCNA does not immediately follow from principles that we are committed to on independent a priori grounds. As it turns out, for all Douven has proven, both the KNA and RCNA defender need a further argument for their preferred account of normativity of belief in order to get support from Douven's 'zeroth law of rationality'. So no advantage here on either side. 
Further on, I have conceded that RCNA does a fair job in accounting for the unassertability of lottery propositions and for the practice of challenging assertions by means of 'How do you know?' questions. However, when it comes to Moorean statements, I have argued that, even if we accept Douven's argument for their unassertability, RCNA still fails to account for their paradoxical soundingness. So there's an advantage on KNA's part on this front.

Last but not least, I have also offered a unified defence of KNA against 'blameless speakers' objections, by putting forth a framework for the normativity of assertion in line with the normativity of action in general, so as to escape charges with ad-hoc-ness.

\subsection{Objections}

Now, the RCNA defender might still want to argue that her preferred account offers a simpler explanation of the cases put forth. Douven gives it a go. He argues that it seems simpler, and thus methodologically preferable, to explain our intuitions about false but reasonable assertions without having to appeal to an extra story about how one can breach rules blamelessly (2006: 478).

As much as one might value simplicity, however, the illustrations in the previous section stand as pretty solid proof to the fact that, in this case, it might get us in trouble when it comes to empirical adequacy. Unless Douven provides us with a principled explanation regarding how assertion differs from other actions, simplicity would lead us to conclude that traffic norms are not, in fact, governing driving, just because I'm blameless for violating them due to my broken speedometer. Similarly, the simpler explanation for my not being blameworthy for breaking my promise to Ted, that is, that there is no rule obliging me to keep my promises, would not do either.

Here are two more reasons to resist this objection; first, it is not clear that the fact that KNA needs to account for the relationship between propriety of action and blamelessness in order to explain the above cases speaks towards its lack of a posteriori simplicity. After all, recall that Douven himself tried to account for the a priori simplicity of RCNA by attempting to show that it follows from principles to which we are committed on independent grounds. Similarly, the defence put forth above follows from principles about the normativity of action to which we are committed on independent grounds. So, rather than speaking against KNA, the fact that it is coheres with an account of the normativity of assertion that follows from the normativity of action in general seems to speak in its favour.

Furthermore, one can easily imagine parallel cases against RCNA which will render the latter in need of a similar line of defence. Take, for instance, Williamson's 
(2000) famous train case: suppose that I, knowing that it is urgent for you to get to your destination, shout 'That is your train!' upon seeing a train approach the station. That looks like the right thing to do, even though I do not know that it is your train, nor do I have knowledge-level justification for believing it; I merely believe that there's a fair chance that it is your train, and it's prudentially better for you to check it out. This is a case in which the prudential norm overrides whatever the epistemic norm says and renders me blameless and my assertion all-things-considered proper. Also, even if my assertion is both in breach of RCNA and improper on all other grounds, I might still be blameless for it, if, for instance, the reason why I assert without having any justification whatsoever is because I have been hit over the head with a bat. In fact, Douven (2006) himself acknowledges that "we will need a story about breaching rules blamelessly anyway, regardless of what we are going to say is the rule of assertion". Thus, it does not look like RCNA fares better in what a posteriori simplicity is concerned either.

On the other hand, for all I have shown in section $\S 4$, neither does KNA. Insofar as both norms are compatible with a normative account that explains breaching rules blamelessly by starting from the wider framework of the normativity of action, the two seem to be shoulder to shoulder in this respect.

Thus, up to now, the scoreboard ${ }^{26}$ seems to only feature one extra point on the part of KNA due to its ability to explain the paradoxical flavour of Moorean statements. Now, as things stand, this will do. Say, however, that the RCNA defender will find a way to account for Moorean statements too. In this case, again, RCNA would gain precedence due to its being the weaker and, thus, more userfriendly norm. For this very reason, what I am going to do below is offer the sketch of an argument for the superiority of KNA in terms of a posteriori simplicity. That is, following Douven's strategy, I will try to argue that KNA follows from a posteriori principles that we are independently committed to.

\subsection{Epistemic Goals and A Posteriori Simplicity}

If there's such a thing as an epistemic norm for assertion in the first place, it is plausibly somehow associated with an epistemic goal; ${ }^{27}$ roughly put, it is there to insure that assertion delivers the epistemic goods we are using it for.

\footnotetext{
${ }^{26}$ To be clear, neither Douven nor I mean to attach much theoretical weight to the scorekeeping business (see Douven 2006, 481); rather, its use is merely illustrative.

${ }^{27}$ Note that Douven (2012) himself argues that the epistemic norm of assertion is concerned with maximizing epistemic utility. Importantly, though the claim made here - and needed for this argument - is weaker. It is a claim of mere association between epistemic norms and epistemic goals; as such, it does not, in any way, imply any value theoretic commitments. The teleologist will explain the 'ought' in terms of the 'good'; he will say that the norm is there to guide us in reaching the goal. The
} 
Now, first, notice that I can tell you that $\mathrm{p}$ with many purposes in mind: I might tell you that the weather is nice to the aim of making polite conversation; I can tell you that you have ugly shoes in order to offend you etc. What we are concerned with, however, are the epistemic purposes associated with the practice of assertion: what epistemic goods is assertion meant to deliver?

Second, speech-act theoreticians ${ }^{28}$ distinguish between two types of goals associated with speech acts: essential goals - accompanying every token of the type - and characteristic goals - often attached to tokens of that type. ${ }^{29}$ In what assertion is concerned, presenting $\mathrm{p}$ as true is an essential goal associated with this particular speech act: one cannot assert that $\mathrm{p}$ without presenting $\mathrm{p}$ as true. When it comes to its characteristic aim, generating true belief/knowledge in the hearer are taken to be obvious candidates; most assertions will be directed at this aim. Although not essentially - I can, say, make assertions in a diary, which are plausibly not intended to affect no audience in any way -, characteristically, assertions will aim at generating true belief/knowledge in the audience. Furthermore, plausibly enough, this is the main social function of assertion to begin with.

Now, crucially, notice that, for actions in general, norms governing them tend to be associated with their characteristic rather than their essential purposes. Consider any action governed by norms, say for instance chess; plausibly, similarly to any game, the characteristic aim of chess playing is enjoying oneself. As such, like all other games, chess playing is governed by a set of rules that are there to insure a high probability of that happening. That is not to say, however, that enjoying oneself is an essential aim of chess; surely one can play chess for several other purposes, like, for instance, teaching someone else how to do it. That, however, again, does not imply that separate norms will be in place in this situation. Thus, it looks as if, when it comes to other types of action, the characteristic goal dictates the content of the relevant norm. ${ }^{30}$

Assertion is a type of action. In line with other types of action, then, we should expect the norms regulating it to be concerned with its characteristic aim. Furthermore, we should expect the epistemic norms governing it to be concerned with its characteristic epistemic aim.

deontologist reverses the order of explanation; he would have it that the goal is only valuable in virtue of the fact that the norm gives us reasons to favour it. Anyhow, the mere association claim holds. Thus, the argument that follows can be construed in both consequentialist and deontological terms.

${ }^{28}$ See e.g. Austin (1962), Green (2009).

${ }^{29}$ Which is not to say that what defines a characteristic goal need be frequency. To the contrary, the fact that this particular goal will often be attached to tokens of that type of action suggests an underlying functional explanation, i.e., that is the kind of good that this particular type of action is meant to deliver. For an account along these lines, see, e.g. Graham (2010). Thus, for the purposes of this paper, I use function and characteristic aim interchangeably; nothing hinges on it.

${ }^{30}$ Note that the case of chess is hardly isolated. Similar examples can be construed with many normgoverned activities: driving, speaking a language, studying at the university... 
Now, on one hand, several people take the main epistemic function of assertion to be transmission of true belief (e.g. Graham (2010)). The competing camp (e.g. Kelp (2014), Reynolds (2002)) defends a knowledge goal; according to these authors, the characteristic purpose of assertion is generating testimonial knowledge in the hearer. Due to our physical and cognitive limitations, most of the knowledge we have is testimonial; thus, assertion is one of our main epistemic vehicles. ${ }^{31}$

For our purposes here, we need not decide this issue; on both these accounts, KNA fares better than RCNA. Here is why: all the epistemic aims we have identified so far are factive. If that is the case, however, mere rational credibility on the part of the speaker is not very likely to deliver the epistemic goods: first, uncontroversially, no matter how much justification I have to believe that $p$ is the case, if $p$ is false and I assert that $\mathrm{p}$, my hearer will not get a testimonial true belief that $\mathrm{p}$.

Furthermore, on the knowledge-goal view, KNA looks even more promising. First, given that knowledge is factive, the objection to RCNA above applies, mutatis mutandis, here too. Second, on most if not all accounts of testimony in the literature, ${ }^{32}$ in the vast majority of cases, the speaker needs to know in order to be able to generate knowledge in the hearer. Exceptions are few, and they roughly boil down to two types of cases: first, we have, again, 'selfless asserters' like Stella. Notice, though, that Stella's case will not help the RCNA defender here: after all, Stella is able to generate knowledge in her students because, as it so happens, on top of its being justified, her assertion is true. Secondly, we have 'Compulsive Liar' cases (Lackey 2008). Roughly, what happens in these cases is that, although the speaker intends to lie on a regular basis, some external intervention makes it so that she safely asserts the truth. Again, though, these cases will not help the rational credibility account, given that compulsive liars also violate RCNA.

Also, notice that both of these cases describe fairly unusual scenarios, thus they are highly unlikely to affect the argument from testimony to the knowledge norm in any way. After all, if the characteristic purpose of assertion is generating testimonial knowledge, and in the vast majority of the cases knowledge on the part of the speaker is needed for generating testimonial knowledge in the hearer, it makes sense to have a knowledge norm governing assertion. To see this, consider driving: norms regulating speed limit within city bounds are presumably there to make it so that we arrive safely at our destination. Surely, though, driving $50 \mathrm{~km} / \mathrm{h}$ within city bounds is not always the ideal speed; there are instances when, for instance, overtaking at 80

\footnotetext{
${ }^{31}$ Is all knowledge/true belief on a par in this respect? Some items thereof seem entirely useless (e.g. about the number of blades of grass on my lawn). Perhaps it is more plausible to think that the epistemic goal of assertion is generating interesting true belief/knowledge (see, e.g., Alston 2005 for discussion). For the purposes of this paper, I will take any such restriction on the relevant epistemic goal as read.

${ }^{32}$ See Lackey (2008) for a nice overview.
} 
$\mathrm{km} / \mathrm{h}$ will avoid a major accident. However, presumably, the reason why the norm says 'Drive at most $50 \mathrm{~km} / \mathrm{h}$ within city bounds!' is because, most of the time, that is the ideal speed for safety purposes.

In sum, things seem to stand as follows: on one hand, in the vast majority of cases, assertions need be knowledgeable in order to deliver the epistemic goods they are meant to deliver; also, by Douven's own lights, in the friendly epistemic environment we inhabit, knowledge is readily available. Furthermore, unlike rational credibility, the concept of knowledge is widely mastered and used. If that is the case, it looks as if simplicity speaks in favour of KNA. Given that "the practice of assertion is, in an incontrovertible sense, a part of reality of our making" (Douven 2006, 451), we should expect ourselves to have kept it simple. ${ }^{33}$

\section{Conclusion}

This paper has argued that the knowledge norm of assertion scores better than the main competing account on the market when it comes to both empirical adequacy and simplicity. To this aim, I have first shown that Igor Douven's argument for the superiority of the rational credibility norm in terms of a priori simplicity does not go through. Further on, I have argued that RCNA, as opposed to KNA, is unable to explain the paradoxical flavour of Moorean statements.

I have also put forth a framework for the normativity of assertion as part of a fairly uncontroversial normative framework for action in general, and argued that it helps to defuse several notable objections to KNA.

And, last but not least, I have brought new reasons to believe that KNA fares better than RCNA when it comes to a posteriori simplicity. That is because, I have argued, KNA is compatible with some fairly uncontroversial assumptions about 1) the characteristic function of assertion and 2) the necessary conditions for generating knowledge/true belief in one's hearer.

33 Here is how RCNA might accommodate all this: recall that, according to Douven, due to knowledge being readily available, in most cases, if $\mathrm{p}$ is rationally credible to one, then one also knows that $\mathrm{p}$. In virtue of this, Douven might argue, RCNA assertions will also generate testimonial true belief/knowledge in the hearer in the vast majority of cases. Notice, though, that this explanation falls quite significantly behind the KNA one when it comes to a posteriori simplicity. Secondly, it looks as if RCNA is not even exceptionally well positioned to offer it, as many norms on the market could just as plausibly help themselves to this explanation: the defender of a truth norm will argue that, when we truly believe that $p$, we usually know that $\mathrm{p}$, the defender of a belief norm will say that when we believe that $p$, we usually know that $p$ etc. And, last but not least, again, given that we are talking about a part of reality of our making, and given the readily availability of knowledge and the wide mastering of the concept, in absence of independent grounds to favor RCNA, it is not clear why we should buy this explanation in the first place. Consider the case of driving again: the norm is not: 'Try your best to drive at most $50 \mathrm{~km} / \mathrm{h}$ !', because if you do that, most of the time you are going to actually drive $50 \mathrm{~km} / \mathrm{h}$, and therefore be safe. The norm just says 'Drive at most $50 \mathrm{~km} / \mathrm{h}$ !'. 
Acknowledgements: Many thanks to Chris Kelp, Harmen Ghijsen and Jan Heylen for all the help with this paper and to Chris Kelp's 'Knowledge First Virtue Epistemology' project for financing the research leading to its completion.

\section{References}

Adler, J. (2002). Belief's Own Ethics. Cambridge, MA: MIT Press.

Alston, W. (2005). Beyond 'Justification'. Ithaca NY: Cornell University Press.

Aristotle. (1985). The Nicomachean Ethics. (T. Irwin, Trans.) Indianapolis: Hackett Publishing Co

De Rose, K. (2002). Assertion, Knowledge and Context. Philosophical Review 111.

Douven, I. (2006). Assertion, Knowledge and Rational Credibility. Philosophical Review 115.

Douven, I. (2008). The Lottery Paradox and Our Epistemic Goal. Pacific Philosophical Quarterly, 89: 204-25

Douven, I (2009). Assertion, Moore and Bayes. Philosophical Studies, 144: 361-75.

Douven, I. and Kelp, C. (2012). In Defense of the Rational Credibility Account: a Reply to Casalegno. Dialectica, 66: 289-97.

Frankfurt, H. (1969). Alternate Possibilities and Moral Responsibility. The Journal of Philosophy, vol. 66, no. 23, 829-839.

Gibbons, J. (2013). The Norm of Belief. Oxford: Oxford University Press.

Graham, P. (2010). Testimonial Entitlement and the Function of Comprehension. In Haddock, A., Millar, A., and Pritchard, D., eds., Social Epistemology. New York: Oxford University Press.

Green, M. (2009). Speech Acts. (E. Zalta, Ed.) Retrieved from The Stanford Encyclopedia of Philosophy (Spring 2009 Edition): URL = $<$ http://plato.stanford.edu/archives/spr2009/entries/speech-acts/>.

Grice, P. (1989). Studies in the Way of Words. Cambridge, MA: Harvard University Press.

Haji, I. (1998). Moral Appraisability. Oxford: Oxford University Press.

Hawthorne, J. (2004). Knowledge and Lotteries. Oxford: Oxford University Press

Kelp, C. (2014). The Generating Knowledge Account of Assertion. Manuscript.

Kvanvig, J. (2009). Assertion, Knowledge and Lotteries. In P. G. Pritchard (Ed.), Williamson on Knowledge (pp. 140-160). Oxford: Oxford University Press.

Lackey, J. (2007). Norms of Assertion. Nous 41, 594-626. 
Lackey, J. (2008). Learning from Words: Testimony as a Source of Knowledge. Oxford: Oxford University Press.

Lehrer, K. (1990). Theory of Knowledge. London: Routledge.

Littlejohn, C. (forthcoming). A Plea for Epistemic Excuses. In F. Dorsch and J. Dutant (ed.), The New Evil Demon. Oxford University Press.

Moore, G.E. (1962). Commonplace Book: 1919 - 1953. London: Allen and Unwin.

Reynolds, S. (2002). Testimony, Knowledge and Epistemic Goals. Philosophical Studies, 110: 139-61.

Simion, M (2014). Assertion: Just One Way to Take It Back. Unpublished Manuscript.

Simion, M. (2015). Assertion: Knowledge Is Enough. Synthese. Online First.

Turri, J. (2011). The Express Knowledge Account of Assertion. Australasian Journal of Philosophy 89,1.

Weiner, M. (2005). Must We Know What We Say? Philosophical Review 114: 227251

Williamson, T. (2000). Knowledge and its Limits. Oxford: Oxford University Press.

Williamson, T. (2009). Replies to Critics. In P. G. Pritchard (Ed.), Williamson on Knowledge (pp. 279-385). Oxford: Oxford University Press.

Williamson, T. (2013). Response to Cohen, Comesaña, Goodman, Nagel and Weatherson. Inquiry 56, no. 1: 77-96.

Williamson, T. (forthcoming). Justifications, Excuses and Sceptical Scenarios. In F. Dorsch and J. Dutant (ed.), The New Evil Demon. Oxford University Press.

Zimmerman, M. (1997). Moral Responsibility and Ignorance. Ethics, 107, 410-426. 